Rapid Reviews COVID-19

\title{
Reviews of "SARS-CoV-2 spike protein as a bacterial lipopolysaccharide delivery system in an overzealous inflammatory cascade"
}

Chiranjib Chakraborty, Peter A Ward ${ }^{1}$

1"University of Michigan, Dept of Pathology "

Published on: Feb 14, 2022

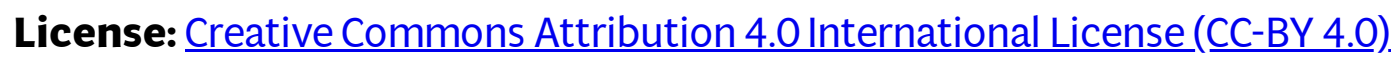


To read the original manuscript, click the link above.

Summary of Reviews: This preprint explores binding of SARS-CoV-2 spike protein with lipopolysaccharide (LPS), and its role in increased inflammatory response. Reviewers find presented evidence reliable, while exercising caution with presented generalizations regarding use of drugs blocking TLR4-LPS binding as potential COVID treatment.

\title{
Reviewer 1 (Chiranjib Chakraborty) | प्ठपढ
}

\section{Reviewer 2 (Peter A Ward)}

To read the reviews, click the links below. 